\title{
Leisure time physical activity and the risk of type 2 diabetes in men and women from the general population
} The MONICA/KORA Augsburg Cohort Study

Received: 7 June 2004 / Accepted: 9 August 2004 / Published online: 23 December 2004

C) Springer-Verlag 2004

\begin{abstract}
Aims/hypothesis: The aim of this study was to examine sex-specific associations between leisure time physical activity and incident type 2 diabetes in a representative population sample in Germany. Methods: The study was based on 4,069 men and 4,034 women (aged 25 to 74 years) who participated in one of the three MONICA Augsburg surveys between 1984 and 1995. Subjects were free of diabetes at baseline. Incident cases of type 2 diabetes were assessed in 1998 using a follow-up questionnaire. Sex-specific hazard ratios (HRs) were estimated from Cox proportional hazard models. Results: A total of 145 cases of incident type 2 diabetes among men and 82 among women were registered during the mean follow-up period of 7.4 years. In both sexes, a high leisure time physical activity level was associated with a reduced risk of incident type 2 diabetes. After adjustment for confounding factors, the HR in highly active men (more than $2 \mathrm{~h}$ physical activity per week in summer and winter) was 0.83 (95\% CI: $0.50-1.36)$. In contrast, highly active women had the lowest risk of type 2 diabetes even after multivariable adjustment (HR 0.24; 95\% CI: 0.06-0.98). In subgroup analyses, after multivariable adjustment, the protective effect of moderate to high physical activity was significant in women with a BMI below $30 \mathrm{~kg} / \mathrm{m}^{2}$ (HR 0.24 ; 95\% CI: 0.09-0.65) but not in women with a BMI of $30 \mathrm{~kg} / \mathrm{m}^{2}$ or higher (HR $0.97 ; 95 \%$ CI: $0.44-2.11$ ). Conclusions/interpretation: Leisure time physical activity is effective in preventing type 2 diabetes, especially in nonobese women, in the general population.
\end{abstract}

C. Meisinger · H. Löwel · B. Thorand · A. Döring Institute of Epidemiology, GSF National Research Center for Environment and Health, Neuherberg, Germany

C. Meisinger $(\triangle)$

MONICA/KORA Myocardial Infarction Registry, Central Hospital of Augsburg,

Stenglinstr 2,

86156 Augsburg, Germany

e-mail: christa.meisinger@gsf.de

Tel.: +49-821-4004373

Fax: $+49-821-4002838$
Keywords Cohort study $\cdot$ Physical activity $\cdot$ Risk $\cdot$ Sex differences - Type 2 diabetes

Abbreviations HR: hazard ratio - KORA: Kooperative Gesundheitsforschung in der Region Augsburg (Cooperative health research in the region of Augsburg) . MONICA: Monitoring trends and determinants on cardiovascular diseases

\section{Introduction}

Currently, it is estimated that 150 million people in the world suffer from diabetes [1]. This number is expected to increase to 300 million by the year 2025; most of these cases will be type 2 diabetes [1]. The prevalence of type 2 diabetes varies widely between populations, reflecting differences in both environmental influences and genetic susceptibility [2]. It is believed that lifestyle changes within populations - characterised by diminished physical activity, increased energy and fat intake, and increased obesity-have interacted with genetic susceptibility to create an epidemic of diabetes. The KORA Survey 2000, a population-based study on prevalence of diabetes and IGT in a 55- to 74-year-old population in Germany reported a total diabetes prevalence of about $17 \%$; an additional $23 \%$ of the population had IGT or IFG. Half of the total cases with diabetes were previously undiagnosed [3]. Thus, the prevalence of abnormal glucose tolerance found in southern Germany is among the highest reported in European countries [4-6], emphasising the need for prevention. It has been shown that physical activity is one of the most important modifiable factors in the prevention of type 2 diabetes, because physical training, even in the absence of weight loss, can increase insulin sensitivity and improve glucose tolerance [7]. Recent findings of two intervention studies $[8,9]$ have shown that incidence of type 2 diabetes can be decreased by $58 \%$ in individuals with IGT through diet and exercise. Also, a number of prospective studies reported that higher levels of physical activity reduced the risk of type 2 diabetes [10-15]. Most of these studies were 
performed in specific groups of subjects, for example in male physicians [11], in female nurses [12], or in male alumni from the University of Pennsylvania [10]. Data on the association of physical activity and risk of type 2 diabetes in men and women from the general population are rather scarce. The present study examined prospectively whether leisure time physical activity is independently associated with reduced risk of type 2 diabetes among men and women from a representative population sample in Germany.

\section{Subjects and methods}

Study population The presented data were derived from the population-based MONICA (Monitoring trends and determinants on cardiovascular diseases) Augsburg studies conducted between 1984 and 1995. The MONICA Augsburg project was part of the multinational WHO MONICA project and the designs of the two projects have been described in detail elsewhere $[16,17]$. Three independent cross-sectional surveys were carried out in the city of Augsburg (southern Germany) and the counties Augsburg and Aichach-Friedberg in 1984/85 (S1), 1989/90 (S2) and 1994/95 (S3) to estimate the prevalence and distribution of cardiovascular risk factors among men and women. Altogether, 13,428 persons $(6,725$ men and 6,703 women; response $77 \%$ ) aged 25 to 74 years participated in at least one of the three cross-sectional studies.

Within the framework of the 'Kooperative Gesundheitsforschung in der Region Augsburg' (KORA; Cooperative health research in the region of Augsburg), vital status was assessed for all sampled persons of the three MONICA surveys through the population registries in 1998. In the meantime, 772 participants $(531$ men, 241 women) have died. Vital status could not be assessed for 56 persons ( 31 men, 25 women) who had moved to a foreign country or to an unknown location. A questionnaire assessing the health status was mailed to the remaining 12,600 living persons (6,163 men, 6,437 women) with known addresses in 1998. A total of 8,548 subjects (4,210 men, 4,338 women) returned the questionnaire (total response rate $67.8 \%$; response rate for men $68.3 \%$, for women $67.4 \%$ ).

We excluded from the present analysis men and women with prevalent diabetes $(n=405)$ and another 43 subjects because of missing values on the question of whether the study participants had diabetes at baseline examination. Furthermore, we excluded subjects for whom diabetes status at follow-up could not be validated $(n=81)$ or for whom no calendar year for the diagnosis of diabetes was available $(n=11)$, and subjects with types of diabetes other than type $2(n=5)$. Four incident cases of diabetes were excluded because these subjects reported a year of diagnosis in the follow-up questionnaire that was before the year of the MONICA baseline examination, even though they had initially reported no diagnosis of diabetes at baseline. Furthermore, we excluded all men and women with missing data on any of the considered risk factors $(n=255)$. Also, subjects with a history of myocardial infarction or a history of angina pectoris at baseline examination were excluded $(n=413)$, because these diagnoses may have led to change in physical activity levels. Finally, the prospective analyses comprised 8,103 nondiabetic MONICA participants (4,069 men and 4,034 women) aged 25 to 74 years.

All participants gave their informed consent and the study was approved by the ethics committee of the Bavarian Medical Association.

Data collection Baseline information on sociodemographic variables, smoking habits, physical activity level, medication use, parental history of diseases, and alcohol consumption were gathered by trained medical staff (mainly nurses) during a standardised face-to-face interview. In addition, all participants underwent an extensive standardised medical examination including collection of a nonfasting blood sample. All measurement procedures have been described elsewhere in detail $[18,19]$. BMI was calculated as weight in kilograms divided by height in square metres. Persons aware of having hypertension, taking antihypertensive medication, and/or having blood pressure values of $160 / 95 \mathrm{mmHg}$ or higher at baseline were defined as actual hypertensives. Dyslipidaemia was defined as total cholesterol/HDL cholesterol ratio being 5 or higher. Education level was categorised into 'low' $(<12$ years of schooling) and 'high' ( $\geq 12$ years of schooling). Subjects were assigned to the positive parental history category if at least one parent had diabetes. If neither parent had diabetes, subjects were assigned to the negative parental history category. Subjects who answered 'I don't know" for both parents or "I don't know" for one parent and "no" for the other parent were assigned to the unknown parental history category. A regular smoker was defined as a subject who currently smoked at least one cigarette per day.

Assessment of physical activity The physical activity level was estimated by means of two separate four-category interview questions asking about the time per week spent on sports activities during leisure time (including cycling) in summer and winter. The winter and summer responses were combined to create one variable of leisure time physical activity. First, participants were classified into one of four categories for frequency of leisure time activity: (1) 'No activity' was defined as no sports in summer or winter; (2) 'Low activity' was irregular participation in sports for about $1 \mathrm{~h}$ per week in at least one season; (3) 'Moderate activity' was defined as regular participation in sports for about $1 \mathrm{~h}$ per week in at least one season; (4) 'High activity' was defined as regular sports in summer and winter for more than $2 \mathrm{~h}$ per week in both seasons. Second, because of the small number of incident type 2 diabetes cases for subgroup analyses, the moderate activity level and the high activity level were combined. 
Ascertainment of diabetes and date of diagnosis In the follow-up questionnaire, persons were asked "Do you have diabetes mellitus?" The question could be answered with "yes" or "no". The calendar year of diagnosis was also ascertained by questionnaire. Self-reported incident cases of diabetes mellitus $(n=283)$ and date of diagnosis was validated by hospital records or by contacting the proband's treating physician. Because 119 of the 772 participants who died during the follow-up period had diabetes at baseline, only the hospital records of those deceased without a diagnosis of type 2 diabetes at baseline $(n=653)$ were also examined and/or their last treating physicians contacted. The records were searched for, or the doctors were asked for a history of diabetes, and if a person had suffered from diabetes, the type of diabetes and the date of diagnosis were ascertained. If a participant was not found in any of the medical records and if no information from the last treating physician could be obtained, the participant was excluded from analysis $(n=75)$.

Statistical analysis The duration of follow-up was calculated as the interval between the baseline examination and (1) the diagnosis of type 2 diabetes, (2) death, or (3) the date when the 1998 questionnaire was completed. Analyses were carried out separately in men and women. Age- and survey-adjusted mean values or percentages of variables considered to be related to physical activity or prognosis were displayed by categories of leisure time physical activity. Means and prevalences were adjusted for age and survey using general linear models. Cox proportional hazards analysis was used [20] to estimate the effect of physical activity on the risk of type 2 diabetes. We calculated hazard ratios (HRs) and 95\% CIs with the category 'no activity' as the reference group. To assess how the association of physical activity with incident type
2 diabetes was affected by other factors, we computed three sequential models. The first model included physical activity, and in addition age (continuous) and survey. The second model included all previous factors plus actual hypertension (yes, no), dyslipidaemia (yes, no), parental history of diabetes (yes, no, unknown), regular smoking (yes, no), alcohol intake (men $0,>0$ and $<40$, or $\geq 40 \mathrm{~g} /$ day; women $0,>0$ and $<20$, or $\geq 20 \mathrm{~g} /$ day) and education ( $<12$ years, $\geq 12$ years). The third model included BMI (continuous) in addition to all factors in model 2. Significance tests were two-tailed and $p$ values less than 0.05 were considered statistically significant. All analyses were performed using the Statistical Analysis System (version 8.2; SAS Institute, Cary, NC, USA).

\section{Results}

In total, 145 incident cases of type 2 diabetes among men (3.6\%) and 82 among women $(2.0 \%)$ were registered in the 25- to 74-year-old study population between 1984 and 1998. The mean follow-up period was 7.4 years with a minimum of 6 days and a maximum of 13.8 years.

Table 1 (men) and Table 2 (women) describe the ageand survey-adjusted baseline characteristics by physical activity categories. Compared with persons in the no activity category, persons in the three higher physical activity categories were younger, less likely to be hypertensive and obese, less likely to have an unknown parental history of diabetes, and less likely to be regular smokers. They were more likely to drink moderate alcohol, and more likely to have an education of 12 years or longer. In men, dyslipidaemia was only less prevalent in the high activity group, whereas in women dyslipidaemia decreased with increasing activity level. In contrast to men, highly active
Table 1 Age- and surveyadjusted means and prevalences of baseline variables according to physical activity level, men

\begin{tabular}{|c|c|c|c|c|}
\hline $\begin{array}{l}\text { Variables } \\
\text { Men }(n=4,069)\end{array}$ & $\begin{array}{l}\text { No } \\
\text { activity } \\
(n=1,109)\end{array}$ & $\begin{array}{l}\text { Low activity } \\
\text { level } \\
(n=1,039)\end{array}$ & $\begin{array}{l}\text { Moderate activity } \\
\text { level } \\
(n=937)\end{array}$ & $\begin{array}{l}\text { High activity } \\
\text { level } \\
(n=984)\end{array}$ \\
\hline \multicolumn{5}{|l|}{ Sociodemography } \\
\hline $\operatorname{Age}^{\mathrm{a}}$ (years) & 51.9 & 47.4 & 44.5 & 44.7 \\
\hline Living alone $(\%)$ & 7.6 & 7.2 & 7.0 & 8.2 \\
\hline Employed (\%) & 83.6 & 86.6 & 86.1 & 85.5 \\
\hline Education $(<12$ years, \%) & 71.6 & 63.7 & 53.6 & 56.2 \\
\hline \multicolumn{5}{|l|}{ Risk profile } \\
\hline Obesity (BMI $\left.\geq 30 \mathrm{~kg} / \mathrm{m}^{2}, \%\right)$ & 20.0 & 16.8 & 14.4 & 12.1 \\
\hline Actual hypertension (\%) & 21.3 & 19.8 & 20.2 & 15.3 \\
\hline Dyslipidaemia (\%) & 44.3 & 48.5 & 43.8 & 38.8 \\
\hline Regular smoking (\%) & 32.7 & 27.0 & 22.2 & 21.3 \\
\hline \multicolumn{5}{|l|}{ Alcohol intake } \\
\hline 0 g/day $(\%)$ & 17.8 & 12.5 & 13.7 & 15.3 \\
\hline $0.1-39.9$ g/day $(\%)$ & 48.2 & 52.1 & 56.1 & 51.9 \\
\hline$\geq 40 \mathrm{~g} /$ day $(\%)$ & 33.6 & 35.0 & 29.8 & 32.4 \\
\hline \multicolumn{5}{|l|}{ Parental history of diabetes } \\
\hline Yes $(\%)$ & 15.6 & 19.3 & 19.3 & 17.7 \\
\hline No $(\%)$ & 61.1 & 62.1 & 64.2 & 64.2 \\
\hline Unknown $(\%)$ & 22.2 & 18.0 & 15.8 & 17.3 \\
\hline
\end{tabular}


Table 2 Age- and surveyadjusted means and prevalences of baseline variables according to physical activity level, women

${ }^{a}$ Only survey-adjusted

\begin{tabular}{|c|c|c|c|c|}
\hline $\begin{array}{l}\text { Variables } \\
\text { Women }(n=4,034)\end{array}$ & $\begin{array}{l}\text { No } \\
\text { activity } \\
(n=1,244)\end{array}$ & $\begin{array}{l}\text { Low activity } \\
\text { level } \\
(n=1,081)\end{array}$ & $\begin{array}{l}\text { Moderate activity } \\
\text { level } \\
(n=1,149)\end{array}$ & $\begin{array}{l}\text { High activity } \\
\text { level } \\
(n=560)\end{array}$ \\
\hline \multicolumn{5}{|l|}{ Sociodemography } \\
\hline $\operatorname{Age}^{\mathrm{a}}$ (years) & 51.0 & 45.4 & 43.5 & 44.4 \\
\hline Living alone $(\%)$ & 9.3 & 8.8 & 9.7 & 13.2 \\
\hline Employed (\%) & 45.2 & 46.2 & 47.8 & 50.3 \\
\hline Education $(<12$ years, \%) & 85.2 & 79.4 & 78.8 & 73.6 \\
\hline \multicolumn{5}{|l|}{ Risk profile } \\
\hline Obesity (BMI $\left.\geq 30 \mathrm{~kg} / \mathrm{m}^{2}, \%\right)$ & 18.7 & 15.4 & 11.7 & 11.0 \\
\hline Actual hypertension (\%) & 14.5 & 12.0 & 9.5 & 7.8 \\
\hline Dyslipidaemia (\%) & 16.4 & 15.7 & 11.8 & 9.4 \\
\hline Regular smoking (\%) & 16.1 & 17.3 & 12.8 & 14.2 \\
\hline \multicolumn{5}{|l|}{ Alcohol intake } \\
\hline 0 g/day (\%) & 47.1 & 38.8 & 35.6 & 33.7 \\
\hline $0.1-19.9 \mathrm{~g} /$ day $(\%)$ & 35.9 & 40.8 & 40.8 & 44.1 \\
\hline$\geq 20$ g/day $(\%)$ & 16.6 & 20.0 & 23.2 & 21.8 \\
\hline \multicolumn{5}{|l|}{ Parental history of diabetes } \\
\hline Yes $(\%)$ & 20.9 & 21.4 & 21.0 & 18.7 \\
\hline No $(\%)$ & 61.6 & 64.0 & 65.1 & 69.1 \\
\hline Unknown (\%) & 16.5 & 14.0 & 13.1 & 11.6 \\
\hline
\end{tabular}

women were more likely to live alone in comparison with inactive women.

Table 3 describes the observed crude incidence rates of diabetes mellitus by physical activity categories. In all leisure time physical activity categories, diabetes incidence was higher in men than in women, but diabetes incidence decreased with increasing activity level in both sexes. The male/female ratio increased with increasing activity level and was most pronounced in the highly active group (male/female ratio 6.5). In Cox proportional hazards models, categories of physical activity were significantly associated with incident type 2 diabetes in both sexes (Table 3). Compared with inactive men (no sports in summer or winter), the age- and survey-adjusted HR of incident type 2 diabetes among highly active men (sports in summer and in winter for more than $2 \mathrm{~h}$ per

Table 3 Relative risks of type 2 diabetes according to physical activity level among men and women

\begin{tabular}{|c|c|c|c|c|c|}
\hline & No activity & Low activity level & Moderate activity level & High activity level & $p$ value for trend \\
\hline Mean BMI $\left(\mathrm{kg} / \mathrm{m}^{2}\right)$ & 27.4 & 27.1 & 26.7 & 26.4 & \\
\hline Person-years (PY) & 7,507 & 7,940 & 7,000 & 7,227 & \\
\hline $\begin{array}{l}\text { Crude incidence per } 10,000 \text { PY } \\
\text { HR }(95 \% \mathrm{CI})\end{array}$ & 78.6 & 50.4 & 32.9 & 31.8 & \\
\hline Model 2 & 1.0 & $0.86(0.57-1.29)$ & $0.73(0.45-1.20)$ & $0.73(0.45-1.20)$ & 0.1425 \\
\hline Model 3 & 1.0 & $0.91(0.61-1.38)$ & $0.76(0.47-1.25)$ & $0.83(0.50-1.36)$ & 0.3063 \\
\hline Women $(n=4,034)$ & $(n=1,244)$ & $(n=1,081)$ & $(n=1,149)$ & $(n=560)$ & \\
\hline Mean BMI $\left(\mathrm{kg} / \mathrm{m}^{2}\right)$ & 27.0 & 25.6 & 25.0 & 24.7 & \\
\hline No. of incident cases & 43 & 24 & 13 & 2 & \\
\hline Model 2 & 1.0 & $0.85(0.51-1.41)$ & $0.59(0.31-1.11)$ & $0.21(0.05-0.86)$ & 0.0085 \\
\hline Model 3 & 1.0 & $0.87(0.52-1.45)$ & $0.70(0.37-1.33)$ & $0.24(0.06-0.98)$ & 0.03 \\
\hline
\end{tabular}

Model 1: age- and survey-adjusted

Model 2: adjusted for age, survey, actual hypertension, dyslipidaemia, parental history of diabetes, regular smoking, alcohol intake, education

Model 3: adjusted for the same variables as model 2 and for BMI 


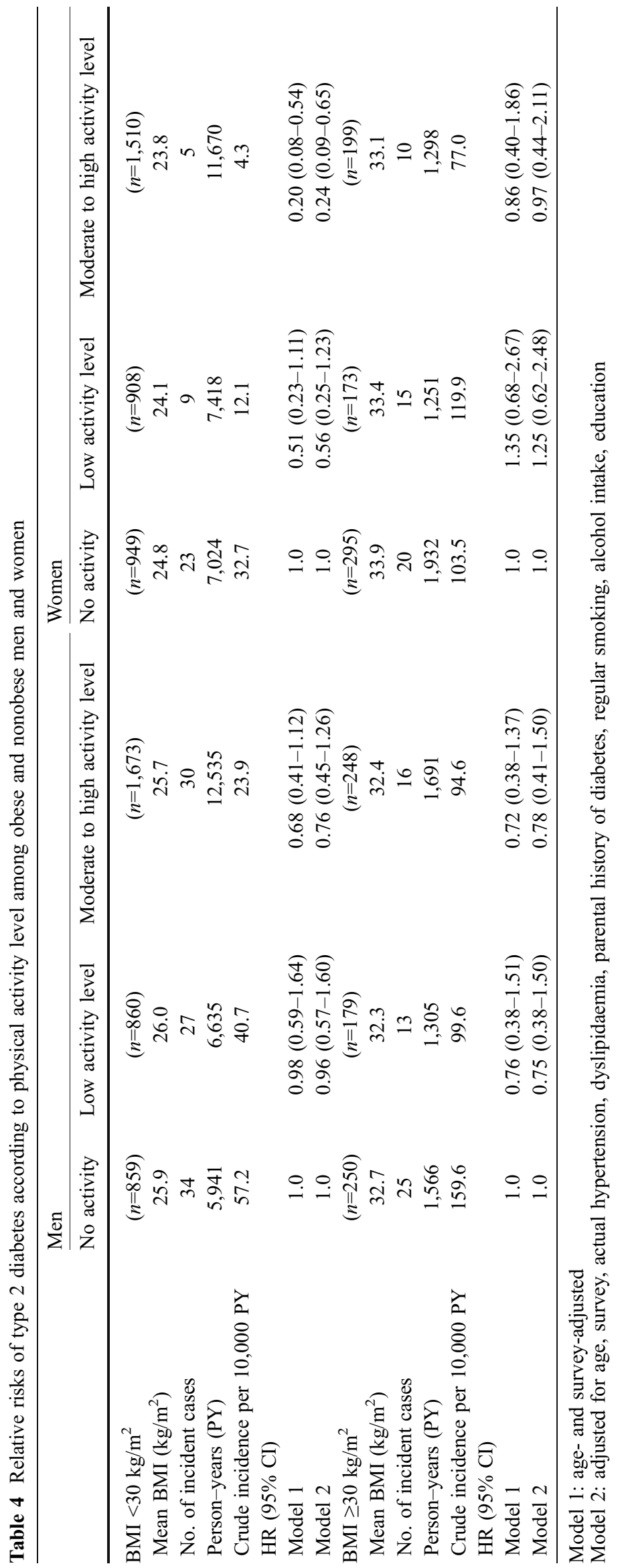


week in both seasons) was 0.62 (95\% CI: 0.38-1.02). Highly active women had an HR of 0.15 (95\% CI: $0.04-$ $0.60)$ after adjustment for age and survey in comparison with inactive women. After adjusting for age, survey, actual hypertension, dyslipidaemia, parental history of diabetes, regular smoking, alcohol intake and education, the HR for highly active men and women was attenuated. In men the HR was not significant anymore, but in women the HR remained significantly reduced (HR $0.21 ; 95 \% \mathrm{CI}$ : 0.05-0.86). Additional adjustment for BMI further attenuated the associations in both sexes; nevertheless, a high physical activity level remained significantly associated with a reduced risk of incident type 2 diabetes in women (HR 0.24; 95\% CI: 0.06-0.98).

To assess whether leisure time physical activity would reduce the risk of type 2 diabetes for both nonobese (BMI $\left.<30 \mathrm{~kg} / \mathrm{m}^{2}\right)$ and obese $\left(\right.$ BMI $\left.\geq 30 \mathrm{~kg} / \mathrm{m}^{2}\right)$ men and women, we analysed the impact of physical activity on the incidence of type 2 diabetes separately for the two groups (Table 4). A reduction in risk among persons who were moderately to highly active was observed for nonobese women in age- and survey-adjusted analysis (HR 0.20; 95\% CI: $0.08-0.54$ ) but not in men (HR 0.68; 95\% CI: $0.41-1.12)$. The observed risk reduction in women remained significant even after multivariable adjustment (HR 0.24; 95\% CI: 0.09-0.65). Among persons with a BMI of $30 \mathrm{~kg} / \mathrm{m}^{2}$ or higher, a nonsignificant reduced risk of diabetes mellitus was observed in moderately to highly active men (HR 0.78; 95\% CI: 0.41-1.50) and women (HR 0.97; 95\% CI: 0.44-2.44) in multivariable analysis. Further adjustment for BMI in each subgroup did not alter these results (data not shown).

\section{Discussion}

In this large cohort of men and women, drawn from the general population, leisure time physical activity was associated with a reduced risk of type 2 diabetes; incidence rates decreased with increasing physical activity level in both sexes. After adjustment for age, survey, BMI, actual hypertension, dyslipidaemia, parental history of diabetes, regular smoking, alcohol intake and education, this association remained significant in women but not in men. Furthermore, the present study suggested that leisure time physical activity may be less effective for the prevention of type 2 diabetes in obese persons than in nonobese persons.

Previous prospective studies mostly performed in specific groups reported that regular physical activity is associated with decreased risk of type 2 diabetes [10-12, $14,21,22]$. In the Nurses Health Study, physical activity was inversely related to the incidence of type 2 diabetes among women aged 34 to 59 years at baseline who reported engaging in vigorous exercise at least once a week in comparison with women who did not exercise weekly [12]. In a study of male alumni from the University of Pennsylvania [10], a negative association between leisure time physical activity (in kilocalories expended per week) and type 2 diabetes was observed. The association was particularly evident in men at high risk of developing diabetes, defined as those with a high BMI, a history of hypertension, or a parental history of diabetes. Similar findings were observed between vigorous exercise and type 2 diabetes in a prospective study of male physicians aged 40 to 84 years [11]. Furthermore, in the Iowa Women's Health Study Cohort [23], women who reported any physical activity had a relative risk of diabetes of 0.69 (95\% CI: 0.63-0.77) compared with sedentary women. Hu et al. found that both walking and vigorous activity are associated with a substantial reduction in risk of type 2 diabetes in women [15]. Further results from the Nurses Health Study suggested that, independently of exercise levels, sedentary behaviours, especially TV watching, were associated with significantly elevated risk of type 2 diabetes and obesity, whereas even light to moderate activities were associated with a substantially lower risk [24]. Also, an inverse association between exercise and incidence of type 2 diabetes was observed among residents of the UK [21, 25] and Finland [13, 26]. The findings in the present study extend the literature showing that leisure time physical activity is associated with a reduction in risk of type 2 diabetes. However, the prospective relationship in this population-based study was stronger in women than in men. This difference may be partly due to the differences in the intensity and the kind of leisure time physical activity performed by the two sexes. There is possibly a sex-specific threshold intensity of physical activity required for diabetes prevention. The Ischemic Heart Disease Risk Factor Study has quantified the relationship between the intensity and the amount of physical activity necessary to gain protection against type 2 diabetes [22]. The results of that study were consistent with a threshold approach, because lower-intensity activities $(<5.5$ metabolic units), regardless of their duration, were not associated with protection from type 2 diabetes in middle-aged men [22]. Furthermore, assuming that more physically active women also eat more healthily, in the present study, part of the large risk reduction among women in the highly active group may also be a result of a healthier diet.

In the present study, risk reduction with exercise was more beneficial for nonobese than for obese persons and particularly evident among nonobese women. Several studies reported that physical activity may be more beneficial for obese subjects $[10,11,22]$; other studies suggested that physical activity may be less beneficial for obese persons than for nonobese persons, or equally beneficial [12, 27]. The present result is consistent with the theory that physical activity prevents diabetes by reducing adiposity. Lower adiposity improves insulin sensitivity and glucose tolerance $[28,29]$. Conversely, obese persons are less likely to engage in physical activity, because excess body weight may decrease the possibility of being physically active. Therefore, in the Augsburg Cohort Study, among physically active obese women, an additional weight loss could substantially lower the risk of type 2 diabetes. Thus, those women in particular should be 
recommended to engage in physical activity and consume a low-energy dense diet to reduce body weight. Although in the present study leisure time physical activity among obese and nonobese men was not intensive enough to significantly reduce the risk of type 2 diabetes, it could nevertheless have a positive effect on cardiovascular risk factors and on the various components of the metabolic syndrome. This assumption is confirmed by Wannamethee et al [25], who reported that the relationship between physical activity and type 2 diabetes appears to be mediated by serum true insulin level and components of the insulin resistance syndrome. Furthermore, the Insulin Resistance Atherosclerosis Study demonstrated a positive association between both vigorous and nonvigorous physical activity and insulin sensitivity in a cross-sectional study of 1,467 men and women [30]. Also, recent clinical trials in China, Finland and the United States have demonstrated that lifestyle intervention programmes (dietary intervention and exercise intervention) were effective in the prevention of diabetes and in the improvement of several cardiovascular disease risk factors [8, 9, 31].

The MONICA/KORA Augsburg Study has several limitations that need to be considered. It is likely that the group of nondiabetic persons may include subjects with undetected diabetes mellitus. This implies that the observed hazard ratios in the present study may underestimate the effect of leisure time physical activity on total diabetes incidence. However, it is also possible that undetected type 2 diabetes at baseline could lead to overestimation of risk reduction, because individuals with undetected type 2 diabetes at baseline might have felt fatigued and therefore reduced the amount of leisure time sports. Furthermore, we were unable to differentiate between persons with normal glucose metabolism and those with borderline hyperglycaemia at baseline examination and at follow-up. Moreover, the follow-up proportion of our study was $67.8 \%$; male respondents were slightly older, had the same BMI and were physically more active in comparison with the male nonrespondents. Women who did return the questionnaire were slightly younger, had a lower BMI, and were physically more active than women who did not respond to the mailing. Thus, response bias cannot be excluded. In the present study only self-reported information on physical activity was available. Possibly, the questionnaire used may be less sensitive to register sex-specific differences in physical activity levels. Also, there may be sex differences in the validity of self-reported information on leisure time physical activity. Additionally, the present study focused on leisure time activity only. Because leisure time physical activity accounts for a small proportion of the day and therefore for a small percentage of total energy output, nonleisure energy expenditure may be also important in the prevention of chronic diseases [32]. A further limitation is the absence of data on changes in exercise throughout the follow-up period. Therefore, a more detailed assessment of physical activity, with regular updates, might have disclosed a stronger benefit of physical activity in relation to type 2 diabetes. The strengths of the
MONICA/KORA Augsburg Cohort Study are primarily its prospective design, the representativeness of the cohort, based on a random sample of the general population, and the availability of data on lifestyle and multiple cardiovascular risk factors. Furthermore, in contrast to most other prospective studies of this kind in which diagnosis of diabetes was based upon self-reporting, diabetes diagnosis in the present study was based on physician-validated diagnosis of type 2 diabetes.

In conclusion, the results from the present study suggest that women from the general population profit more from leisure time physical activity than men in reducing the risk of type 2 diabetes. However, further research is needed to assess the intensity, duration and frequency of exercise that will be most effective in reducing the incidence of type 2 diabetes in subjects from the general population. Recommendations for physical activity need to be tailored to special features of men and women, to personal preferences, age, social and economic circumstances, and physical limitations. Also, there may be need for recommendations for preventing weight gain or regain in normalweight and formerly obese individuals respectively.

Acknowledgements The KORA research platform and the MONICA Augsburg studies were initiated and financed by the GSF-National Research Centre for Environment and Health, which is funded by the German Federal Ministry of Education, Science, Research and Technology and by the State of Bavaria. We wish to thank the company Socialdata (Munich; MONICA Augsburg survey 1984/85) and the company B. Schwertner (Augsburg; MONICA Augsburg surveys 1989/90 and 1994/95) for the organisation and realisation of the surveys and the follow-up questionnaire in 1998. We thank all members of the GSF Institute of Epidemiology who were involved in the planning and conduct of the study. We also thank U. Keil (University of Münster, Germany) as principal investigator of the MONICA Augsburg study. Finally, we express our appreciation to all study participants.

\section{References}

1. King H, Aubert R, Herman W (1998) Global burden of diabetes, 1995-2025: prevalence, numerical estimates and projections. Diabetes Care 21:1414-1431

2. Amos A, McCarty D, Zimmet P (1997) The rising global burden of diabetes and its complications: estimates and projections to the year 2010. Diabet Med 14:S1-S85

3. Rathmann W, Haastert B, Icks A et al (2003) High prevalence of undiagnosed diabetes mellitus in southern Germany: target populations for efficient screening. The KORA survey 2000. Diabetologia 46:182-189

4. Tuomilehto J, Korhonen HJ, Kartovaara L et al (1991) Prevalence of diabetes mellitus and impaired glucose tolerance in the middle-aged population of three areas in Finland. Int $J$ Epidemiol 20:1010-1017

5. Mooy JM, Grootenhuis PA, de Vries H et al (1995) Prevalence and determinants of glucose intolerance in a Dutch Caucasian population. The Hoorn Study. Diabetes Care 18:1270-1273

6. Stolk RP, Pols HAP, Lamberts SWJ et al (1997) Diabetes mellitus, impaired glucose tolerance, and hyperinsulinemia in an elderly population. The Rotterdam Study. Am J Epidemiol $145: 24-32$

7. Ivy JL, Zderic TW, Fogt DL (1999) Prevention and treatment of non-insulin-dependent diabetes mellitus. Exerc Sport Sci Rev 27:1-35 
8. Tuomilehto J, Lindström J, Eriksson J et al (2001) Prevention of type 2 diabetes mellitus by changes in lifestyle among subjects with impaired glucose tolerance. $\mathrm{N}$ Engl J Med 344:1343-1350

9. Knowler WC, Barrett-Connor E, Fowler SE et al (2002) Reduction in the incidence of type 2 diabetes with lifestyle intervention or metformin. N Engl J Med 346:393-403

10. Helmrich SP, Ragland DR, Leung RW, Paffenbarger RS Jr (1991) Physical activity and reduced occurrence of non-insulindependent diabetes mellitus. N Engl J Med 325:147-152

11. Manson JE, Nathan DM, Krolewski AS, Stampfer MJ, Willett WC, Hennekens CH (1992) A prospective study of exercise and incidence of diabetes among US male physicians. JAMA 268:63-67

12. Manson JE, Rimm EB, Stampfer MJ et al (1991) Physical activity and incidence of non-insulin-dependent diabetes mellitus in women. Lancet 338:774-778

13. Hu G, Qiao Q, Silventoinen K et al (2003) Occupational, commuting, and leisure-time physical activity in relation to risk for type 2 diabetes in middle-aged Finnish men and women. Diabetologia 46:322-329

14. Burchfiel CM, Sharp DS, Curb JD et al (1995) Physical activity and incidence of diabetes: the Honolulu Heart Program. Am J Epidemiol 141:360-368

15. Hu FB, Sigal RJ, Rich-Edwards JW et al (1999) Walking compared with vigorous physical activity and risk of type 2 diabetes in women: a prospective study. JAMA 282:1433-1439

16. Keil U, Liese AD, Hense HW et al (1998) Classical risk factors and their impact on incident non-fatal and fatal myocardial infarction and all-cause mortality in southern Germany. Results from the MONICA Augsburg Cohort Study 1984-1992. Eur Heart J 19:1197-1207

17. WHO MONICA Project Principal Investigators (prepared by $\mathrm{H}$. Tunstall-Pedoe) (1988) The World Health Organization MONICA Project (Monitoring of Trends and Determinants in Cardiovascular Disease): a major international collaboration. J Clin Epidemiol 34:105-114

18. Hense HW, Filipiak B, Döring A, Stieber J, Liese A, Keil U (1998) Ten-year trends of cardiovascular risk factors in the MONICA Augsburg Region in Southern Germany. Results from the 1984/85, 1989/90 and 1994/1995 surveys. CVD Prev $1: 318-327$

19. Meisinger C, Thorand B, Schneider A, Stieber J, Döring A, Löwel H (2002) Sex differences in risk factors for incident type 2 diabetes mellitus. The MONICA Augsburg Cohort Study. Arch Intern Med 162:82-89
20. Cox DR (1972) Regression models and life tables. J R Stat Soc $34: 187-220$

21. Perry IJ, Wannamethee SG, Walker MK, Thomson AG, Whincup PH, Shaper AG (1995) Prospective study of risk factors for development of non-insulin dependent diabetes in middle aged British men. BMJ 310:560-564

22. Lynch J, Helmrich SP, Lakka TA et al (1996) Moderately intense physical activities and high levels of cardiorespiratory fitness reduce the risk of non-insulin-dependent diabetes mellitus in middle-aged men. Arch Intern Med 156:1307-1314

23. Folsom AR, Kushi LH, Hong CP (2000) Physical activity and incident diabetes mellitus in postmenopausal women. Am J Public Health 90:134-138

24. Hu FB, Li TY, Colditz GA, Willett WC, Manson JE (2003) Television watching and other sedentary behaviors in relation to risk of obesity and type 2 diabetes mellitus in women. JAMA 289:1785-1791

25. Wannamethee SG, Shaper AG, Alberti KGMM (2000) Physical activity, metabolic factors, and the incidence of coronary heart disease and type 2 diabetes. Arch Intern Med 160:2108-2116

26. Haapanen N, Miilunpalo S, Vuori I, Oja P, Pasanen M (1997) Association of leisure time physical activity with the risk of coronary heart disease, hypertension and diabetes in middleaged men and women. Int J Epidemiol 26:739-747

27. Wei M, Gibbons LW, Mitchell TL, Kampert JB, Lee CD, Blair SN (1999) The association between cardiorespiratory fitness and impaired fasting glucose and type 2 diabetes mellitus in men. Ann Intern Med 130:89-96

28. King DS, Dalsky GP, Staten MA, Clutter WE, Van Houten DR, Holloszy JO (1987) Insulin action and secretion in endurancetrained and untrained humans. J Appl Physiol 63:2247-2252

29. Folsom AR, Jacobs DR Jr, Wagenknecht LE et al (1996) Increase in fasting insulin and glucose over seven years with increasing weight and inactivity of young adults: the CARDIA Study. Am J Epidemiol 144:235-246

30. Mayer-Davies EJ, D’Agostino R, Karter AJ et al (1998) Intensity and amount of physical activity in relation to insulin sensitivity. The insulin resistance atherosclerosis study. JAMA 279:669-674

31. Pan XR, Li GW, Hu YH et al (1997) Effects of diet and exercise in preventing NIDDM in people with impaired glucose tolerance. The Da Qing IGT and Diabetes Study. Diabetes Care 20:537-544

32. Weller I, Corey P (1998) The impact of excluding non-leisure energy expenditure on the relation between physical activity and mortality in women. Epidemiology 9:632-635 